\title{
Proceeding
}

Asia Pacific Conference on Performance Analysis of Sport, 21-24 April 2014. Langkawi, Malaysia

\section{Comparison in some kinematic variables of layup basketball of older and young players}

\author{
DR. SURA JAMIL HANNA ${ }^{1}$, DR. SAAD ALLA ABASS ${ }^{2}$ \\ ${ }^{1}$ College of physical education Duhok University \\ ${ }^{2}$ College of physical education Sallah Al deen University
}

\begin{abstract}
Hanna, S.J., Abass, S.A. (2015). Comparison in some kinematic variables of layup basketball of older and young players. J. Hum. Sport Exerc., 9(Proc2), pp.S737-S741. Basketball is a game that requires being fast in either attack and defense with a precision in tactical and technical preparation. Recently in many countries in the world basketball is the second most popular game with its vision attracting techniques. The Research problem was determination of the effect of layup techniques on the score of the basketball games of university players in Mosul, this require proper training methods in which players can practice the best techniques based on the outcomes of analyses. The population of this study was undergraduate male basketball players of the University of Mosul -Iraq, for the academic year 2012-2013, each sample included (6) male basketball players; young players $=(176.7 \mathrm{~cm}$ tall), $(18,3$ years age) older player $=(179.6 \mathrm{~cm}$ tall), (23,3 years age). The older players were better in all tested variables (horzontal and vertical distance, Hips Displacement for jumping, Height of palm, distance of take-off from basket ball). Key words: BASKETBALL, PERFORMANCE ANALYSIS, TECHNIQUES
\end{abstract}

Corresponding author. College of physical education Duhok University.

Asia Pacific Conference on Performance Analysis of Sport, 21-24 April 2014. Langkawi, Malaysia.

JOURNAL OF HUMAN SPORT \& EXERCISE ISSN 1988-5202

(C) Faculty of Education. University of Alicante

doi:10.14198/jhse.2015.10.Proc2.14 


\section{INTRODUCTION}

Basketball is a game that requires being fast in either attack and defense with a precision in tactical and technical preparation.

Recently in many countries in the world basketball is the second most popular game with its vision attracting techniques.

One of the most important skill in basketball is layup, it is one of the five shoting in basketball have two steps and hop (Al Teckretee, 1988). The layup technique can effect on the score dramatically and provide teams winning of the game.

The kinematic is a science that interest in study the outside discretion for the time and place of movements without the powers (Luay \& Ghanim, 1987). However, strength, speed and accuracy are the basic requirements interact with technical for an effective layup, and the kinematic analysis is a type of biomechanics analysis that care of descript the movement and its have three kinds of analysis: quantitative, specific, and educational (Resan \& Nejah, 2002). Therefore, the objective of this study was to investigation biomechanical parameters of layup which can effect on the score and to find out the difference between the layup techniques of players experienced and younger group player of the same university team.

The Research problem was determination of the effect of layup techniques on the score of the basketball games of university players in Mosul, this require proper training methods in which players can practice the best techniques based on the outcomes of analyses.

\section{METHODS}

A descriptive research design used in the current study were:

The population of this study was undergraduate male basketball players of the University of Mosul -Iraq, for the academic year 2012-2013, each sample included (6) male basketball players; young players $=(176.7 \mathrm{~cm}$ tall), $(18,3$ years age $)$ older player $=(179.6 \mathrm{~cm}$ tall $),(23,3$ years age $)$.

Data were analyzed using SPSS version 19.0, Mean variables compared by T-test at 0.05 .

The procedure of this research started with warm up for 15 minutes followed by passing, shooting, the players performed the layup technique by repeated 3 times and the best performance of layup was selected to analyze.

The kinematic variables of the research were: First step length ,Second step length, Speed of second step, Knee angle , Height of palm , Distance of take-off from basket, Horizontal distance, Vertical distance, The distance of hip flight.

First step time, and Second step time.

Programs of Maxtra and Dartdish used for analysis. 

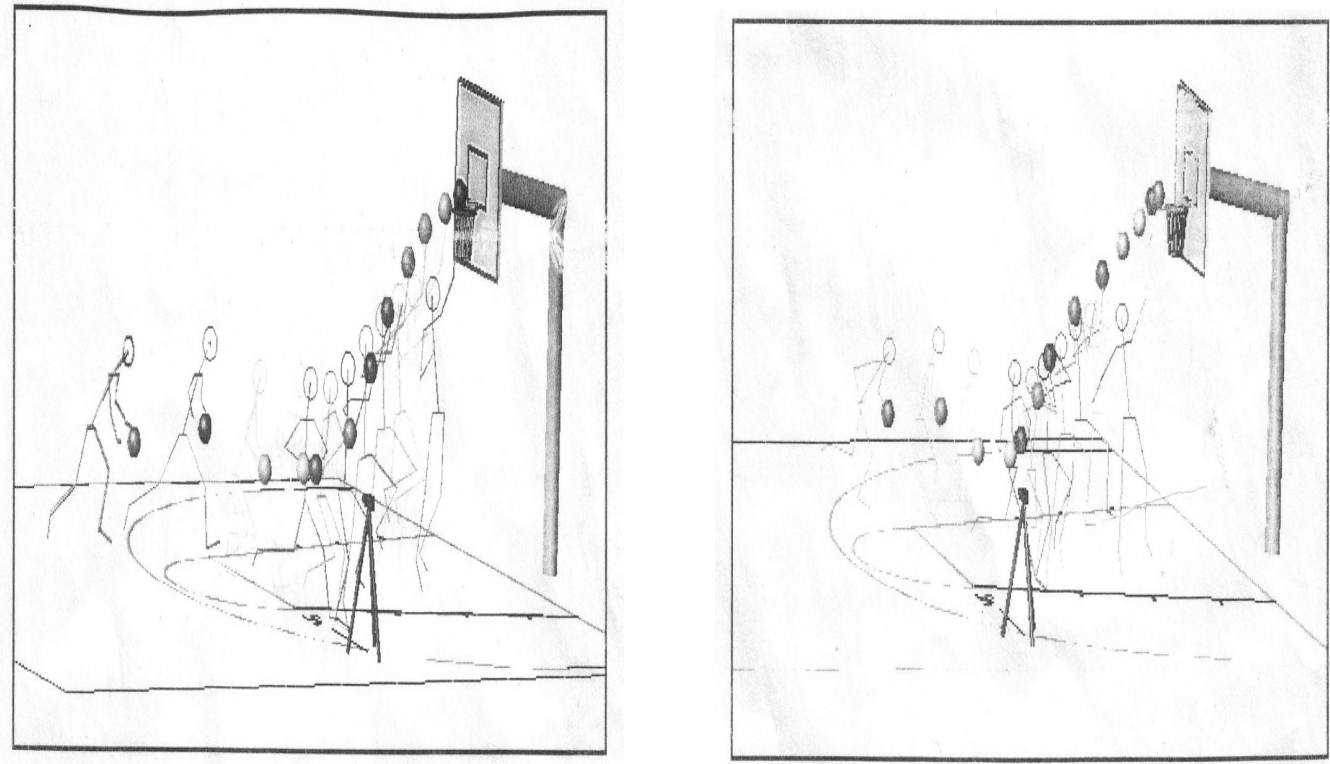

Figure 1. Lay-up scoring and camera position of old and young players. (A) Older player at 23 years old.

(B) Younger players at 19 years old.

Figure 1 show: The lay-up scoring of the older (23) years old (Fig $1 \mathrm{~A}$ ) and young (19) years old (Fig 1 B)describing the path of the ball, the palm and the horizontal and vertical distance of center of gravity and the differences between these variables.

\section{RESULTS}

Table 1. Calculated and table T for kinematic variables (length and speed of First and second step) during layup.

\begin{tabular}{lcccccc}
\hline Scores Variable & \multicolumn{2}{c}{ OLDER } & \multicolumn{2}{c}{ YOUNG } & T-test & Results \\
& (average age of 23) & (Average age of 19) & & \\
\hline & M & SD & M & SD & & \\
First step length $(\mathrm{cm})$ & 130.1 & 1.4 & 96.39 & 2.57 & 23.08 & Significant \\
Second step length $(\mathrm{cm})$ & 112 & 1.15 & 86.89 & 4.33 & 10.17 & Significant \\
Speed of first step $(\mathrm{m} / \mathrm{sec}$ ) & 3.43 & 0.01 & 3.13 & 0.09 & 2.78 & Significant \\
Speed of second step $(\mathrm{m} / \mathrm{sec}$.) & 7.69 & 0.25 & 5.96 & 0.21 & 10.57 & Significant \\
\hline
\end{tabular}

Significant at $0.05, F . D=0,5$ table $T=2.57$

The length of first and second step of older group was $130.1,112 \mathrm{~cm}$ respectively, compared to $96.4 \mathrm{~cm}$ in the first step and $86.9 \mathrm{~cm}$ in the second step of young group.

The speed in the first and second steps of the older group were $3.4 \mathrm{mls}$ and $7.7 \mathrm{ml}$ whereas the younger group have slower score of 3.1 and $6 \mathrm{mls}$.

The differences in speed and length depends on the coordination of strength, power and explosiveness for the older group as Mehdi said "when the player extend the joints of the body when he break out get more distance and more movement area(Mehdi et al.,1988). 
Table 2. Statistical for both class describing the differences of the knee angle and the height and the distance of take -off from basket

\begin{tabular}{|c|c|c|c|c|c|c|}
\hline \multirow[t]{2}{*}{ Scores Variable } & \multicolumn{2}{|c|}{$\begin{array}{c}\text { OLDER } \\
\text { (average age of 23) }\end{array}$} & \multicolumn{2}{|c|}{$\begin{array}{c}\text { YOUNG } \\
\text { (Average age of 19) }\end{array}$} & \multirow[t]{2}{*}{ T-test } & \multirow[t]{2}{*}{ Results } \\
\hline & $M$ & SD & $\mathrm{M}$ & SD & & \\
\hline Knee angle (dgree) & 122 & 1.46 & 124 & 0.7 & 2.57 & Non Significant \\
\hline Height of palm $(\mathrm{cm})$ & 183.6 & 1.3 & 182.4 & 1.07 & 1.59 & Non Significant \\
\hline $\begin{array}{l}\text { Distance of take-off from basket } \\
\text { ball }(\mathrm{cm})\end{array}$ & 118.2 & 1.34 & 109.30 & 1.1 & 11.5 & Significant \\
\hline
\end{tabular}

Significant at $0.05, F . D=0.5 \mathrm{~T}$ table $=2.57$

The average of knee angle value of older group was less than youth group while the height of palm and the distance between take-off and basket were more than for youth group.

Older group had more speed and length of the steps than the youth group especially of the lower body so that they made more jump and more high, but because the less experience for young players, their knee angle was less.

Table 3. Statistically parameters for both class describing the differences of the distances and the time of jumping.

\begin{tabular}{lcccccc}
\hline Scores Variable & \multicolumn{2}{c}{ AVANCED } & \multicolumn{2}{c}{ YOUTH } & T-test & Results \\
& M & SD & M & SD & Significant \\
Horizontal distance $(\mathrm{cm})$ & 58.48 & 1.16 & 49.02 & 0.84 & Significant \\
Vertical distance $(\mathrm{cm})$ & 25 & 1.012 & 14.4 & 1.90 & Significant \\
Hips Displacement for & 58.77 & 0.95 & 50.88 & 1.40 & Significant \\
jumping(cm) & 0.52 & 0.08 & 0.4 & 0.08 & Non Significant \\
Time of first step(second) & 0.2 & 0.08 & 0.2 & 0.13 & \\
Time for second step (second) & 0.2 &
\end{tabular}

\section{Significant at $0.05, F . D=0.5$, Table $t=2.57$}

Horizontal and vertical distance for older group had higher than young.

Hips Displacement for jumping for older was higher than young.

Time of first step for older was higher than young.

Time for second step was same for Bothe of them because the strength of older group was higher so that they can jump better. Thus, there were significant differences in the examined variables studied between the older and the youth groups, these differences may attributed to experience gained from the exercises as well as using their center of mass by break out throw opposite, in this aspect Al Rasheed (1987) reported that "the objective of the player is jump vertically not horizontally in the final steps so that he must to change his horizontal power to vertical power" (AlRasheed, 1987). 


\section{CONCLUSIONS}

The length and speed of first and second step for older players higher for the older player than the youth.

The older players were better in all tested variables (horzontal and vertical distance, Hips Displacement for jumping, Height of palm, distance of take-off from basket ball).

Recommendations

- Make sure for body measurements when choosing basketball players.

- More training for length and speed of step.

- Continuous exercises of lay up from different places.

- Players should be use coordination, strength and accuracy.

- It is important to insure that center of body movement with all other parts during practicing.

\section{REFERENCES}

1. Luay, G. (1987). Biomechanics and Sport: dar al kutub, Mosul University.

2. Kasem,H., \& Eman, S. (1998).Basic mechanics of sport movement: dar al fiker Aman.

3. Mehdi.N., \& others (1988).Development in Phases of Basketball Training: dar al kutaub Mosul university.

4. Resan, K., \& Nejah, M. (2002).Kinetic Analysis: al dar alalemia, Aman.

5. Al teckretee, M. (1988). The Progress in Basketball Levels: university of Musel.

6. Al Rasheed, R. (1987).The Technical Skills in The Basketball: university of Baghdad. 